\title{
Retraction Note to: Development of a screening tool to assess the temporal risk of pesticides leaching to groundwater using the source, target, vector approach. An Irish case study for shallow groundwater
}

\author{
Herve E. Labite • Enda Cummins
}

Published online: 29 July 2015

(C) Springer International Publishing Switzerland 2015

\section{Retraction Note to: Environ Monit Assess (February} 2015) 187, Issue 3:91

DOI 10.1007/s10661-015-4325-9

This article has been retracted by the Editor-in-Chief because the authors did not have permission (implicit or explicit) to publish the data used to validate the model, which was unpublished and was not contained in the cited unpublished $\mathrm{PhD}$ thesis by Sarah McManus (Trinity Centre for the Environment, Dublin, Ireland). Given the copyright and authorship issues involved, the Environmental Monitoring and Assessment article in question is being retracted. The authors apologize for their negligence.

The online version of the original article can be found at http://dx.doi.org/10.1007/s10661-015-4325-9.

H. E. Labite $\cdot$ E. Cummins $(\bowtie)$

UCD School of Biosystems Engineering, College of

Engineering and Architecture, University College Dublin,

Belfield, Dublin 4, Ireland

e-mail: enda.cummins@ucd.ie

H. E. Labite

e-mail: labher@yahoo.fr 